\title{
The Physician on a Board of Directors: Bane or Benefit?
}

\author{
Malke Borow', Baruch Levi ${ }^{1,2}$, Benny Avissar', Leah Wapner' \\ 'Israeli Medical Association, Ramat Gan, Israel; ${ }^{2}$ Department of Health Policy and Management, Ben-Gurion University of the Negev, Beer-Sheva,
} Israel

Correspondence: Baruch Levi, Division of Law and Public Policy, Israeli Medical Association, 35 Jabotinsky St., Ramat Gan, Israel, Tel +972-54-6330935, Email baruch@ima.org.il

\begin{abstract}
With the accelerated development of innovative domains such as artificial intelligence, big data, and personalized healthcare, the continuing growth of health-tech and bio-tech industries is to be expected. Concurrently, the question of the extent and nature of physicians' involvement in these rapidly evolving industries arises, especially in management and leadership capacities such as directors or chief executive officers of such companies. Against this backdrop, the Israeli Medical Association recently launched a first-of-its-kind course designed to train senior physicians as directors in health-tech companies by providing them with vast relevant financial, legislative, and professional proficiencies. Due to their medical knowledge and clinical experience, physicians bring a substantial added value to these industries. However, considering the inherent tensions and potential conflicts between adhering to the logic of a profit-making, competitive market on one hand and maintaining the doctor's oath on the other, it is inevitable that dilemmas and difficulties will emerge. Much has been written about the roles and responsibilities of boards of directors, but to date, little has focused on the unique position of physicians who serve in these roles. This article aims to examine the ways in which conflicts or dualities of interest manifest themselves for physicians who assume roles as directors and whether effective remedial strategies are available, based on the authors' own experience in the initiation of the IMA physician-directors course.
\end{abstract}

Keywords: physicians, directors, health technology, biotechnology, leadership, management, medical ethics

\section{Plain Language Summary}

The Israeli Medical Association recently launched a first-of-its-kind course designed to train senior physicians as directors in healthtech companies by providing them with vast relevant financial, legislative and professional proficiencies. Due to their medical knowledge and clinical experience, physicians' added value to these industries is substantial.

However, considering the inherent tensions and potential conflicts between adhering to the logic of a profit-making, competitive market on one hand and maintaining the doctor's oath on the other, it is inevitable that dilemmas and difficulties will emerge. It is, therefore, necessary for physician-directors to be well versed in their various legal, ethical and professional obligations as physicians, employees and board members. This article seeks to address the particular risks and benefits that accompany the function of physiciandirectors in the industry of medical innovation, and discuss challenges that may arise, based on the authors' own experience in the initiation of the IMA physician-directors course. Finally, the authors also discuss some potential solutions.

\section{Introduction}

David is a respected cardiologist in private practice, as well as on staff at a public hospital in Israel. Because of his knowledge, reputation and professional connections, he has recently been appointed to serve on the board of directors of a new technology start-up company involved in remote cardiac activity monitoring. Although David's benefit to the board in such a case is seemingly apparent, there are potential obstacles for both him as an individual and the board as a legal and organizational entity.

David's hospital is one of the company's largest potential clients. In addition, David is active in the Israeli Cardiology Association, predominantly in preparing clinical guidelines. Naturally, one of the company's most important goals is to 
integrate its device in future medical recommendations in cardiology. Can David fulfill these diverse roles ethically and effectively?

It seems that as long as health technology continues to push the boundaries of how healthcare is delivered while creating breakthroughs in our understanding of disease, hypothetical examples such as the one above will become more and more frequent in the real world. As opposed to many industries that have slowed down during the coronavirus pandemic, the businesses of biotech and health technology have experienced an impressive growth. ${ }^{1,2}$ With the accelerated development of innovative domains such as artificial intelligence, big data and personalized healthcare, the continuing evolution of health-tech and bio-tech industries is expected. Concurrently, the question of the extent and nature of physicians' involvement in these rapidly evolving industries arises, especially in management and leadership capacities such as directors or chief executive officers of such companies.

Physicians' leadership and management skills play a central role and yield superior outcomes for patients and health care delivery organizations. ${ }^{3}$ By the same token, the added value of physicians to innovative health industries, as a result of their medical knowledge and clinical experience, is substantial. However, considering the inherent tensions and potential conflicts between adhering to the logic of a profit-making, competitive market on one hand and maintaining the doctor's oath on the other, it is inevitable that dilemmas and difficulties will emerge.

Much has been written about the roles and responsibilities of boards of directors, ${ }^{4-7}$ but to date, little has focused on the unique position of physicians who serve in these roles. This article aims to examine the ways in which conflicts or dualities of interest manifest themselves for physicians who assume roles as directors and whether effective remedial strategies are available.

\section{Israel as a Study Case}

Although the above is true for practically every economically and technologically developed country, an urgent need to address this issue recently arose in Israel. With more start-ups per capita than any other country, and one of the highest expenditures on research and development as a share of its gross domestic product, Israel consistently appears at the top of international rankings and reports on technological innovation, with biotechnology, medical engineering, pharma and industrial biology garnering a significant portion of investments. ${ }^{8,9}$ Moreover, Israel is among the world's leading countries in the number of biomedical publications per population; its healthcare system has a developed system of electronic records and an evolving digital health program on a national scale. ${ }^{10,11}$

Against this backdrop, the Israeli Medical Association (IMA) recently launched several initiatives aimed at helping physicians bring their added value to the Israeli health-tech and biomedical industries. These initiatives include linking medical residents and health technology start-up companies as an integral part of the residents' medical training, and creating medical innovation fellowships for physicians to impart the tools, language, and skills for successful cooperation between the healthcare system and the industrial sector.

The most prominent initiative thus far, perhaps the crown jewel of IMA's efforts in the field, is the launching of a directorate course for senior physicians. Affiliated with the Hebrew University of Jerusalem, this first-of-its-kind course is designed to train senior physicians as directors in health-tech companies by providing them with vast relevant financial, legislative and professional proficiencies.

There is little doubt that these potential future physician-directors will encounter challenges similar to those presented in David's case. The contents of the course will probably not be sufficient to guide them. While this article in no way proposes a flow chart for decision-making or a list of "dos and don'ts" for fledgling physician-directors, there is arguably merit in shedding light on some principal difficulties and potential pitfalls of physicians serving on directorate boards of health technology companies, based on the authors' own experience in the initiation of the IMA physician-directors course.

\section{What is a Board of Directors?}

A board of directors ("Board") is a group of people whose role is to oversee the activities and proceedings of a commercial company, a non-profit organization or a government agency. The Board is responsible for establishing policies and making decisions about important issues the company or organization faces. A Board is governed both by law and by the organization's statutes and bylaws. 
Sometimes, members of a Board are chosen because of their connection to the essence of the organization they supervise. Thus, a financier may be selected to the Board of a bank, a former pro-baseball player to the Board of a sports team or a physician to the Board of a medical equipment company.

Members of a Board owe specific fiduciary duties, including a duty of care, a duty of loyalty, and obedience. The duty of care includes the ability and responsibility to perform due diligence and make informed decisions based on all material information reasonably available.

The duty of loyalty requires acting independently, in good faith and avoiding conflicts of interest. This duty is delineated at length in the Israeli Companies Law (1999), as including, among other things, any action that poses a conflict between the director's role in the company and his or her role in another capacity or personal life, any action that would compete with the company's business, and any action that takes advantage of the company's business to provide benefit to himself or another. ${ }^{12}$ Notwithstanding the above, the law does provide for activities as listed above to be approved by the Company in specific instances, such as when the director acts in good faith and the action does not harm the Company's good, provided that the director notifies the Company of the potential conflict a reasonable amount of time before they deliberate whether to approve the action. ${ }^{12}$ It is interesting to note that the duty of care is predicated upon the desire to prevent harm to society. Therefore, a breach of this duty under Israeli law assumes actual harm. ${ }^{13}$ In contrast, the duty of loyalty aims to prevent the abuse of a director's power and there is no need to prove actual harm. ${ }^{14}$ The third duty is the duty of obedience, which requires board members to follow all applicable rules and regulations and ensure that the organization is not engaging in unauthorized or illegal activities.

\section{Physicians as Directors: The Challenge of Conflicting Interests}

The fiduciary duties of directors require them to act in the best interest of the company, even when doing so might not be in the director's own personal best interest. But while ordinarily fiduciaries must not let their interest interfere with their professional duties, physicians have, in addition, conflicting professional duties that they must take into account.

An interesting perspective is provided by a solicitor in New Zealand who notes that if physician directors feel that a decision would put patients at risk of harm, they must, under the guidelines of the Medical Council, make their objections known; however, this could lead to conflict with the Public Disclosures Act. In 2011, the Council, noting the inherent conflict, revised their guidelines for physicians serving on governing boards. ${ }^{15}$

When physicians serve as members of a Board, they bring to the table not just fiduciary obligations to the company. Physicians represent not just themselves, but their profession, with its unique nature and all the incumbent professional and ethical commitments it evokes. Physicians are bound by a "social contract" between the profession and society. ${ }^{16}$ As stated by Drs. Richard and Sylvia Cruess:

Society granted physicians status, respect, autonomy in practice, the privilege of self-regulation, and financial rewards on the expectation that physicians would be competent, altruistic, moral, and would address the health care needs of individual patients and society. ${ }^{16}$

Interestingly, these expectations are themselves reminiscent of the fiduciary obligations borne by directors.

Figure 1 illustrates the unique spheres of conflict in which the physician-director may find himself. In addition to the unwritten code of behavior by which physicians are meant to abide, they have an additional, discrete set of rules and regulations to contend with. Along with general legal, ethical and organizational requirements for all directors, the physician must abide by a professional Code of Medical Ethics. Physicians must always engage in behavior "befitting the profession of medicine," avoid any semblance of conflict of interest and hold individual patients at the forefront of their medical considerations. In addition, the Physicians' Ordinance prevents physicians from engaging in any pursuit that might present a conflict of interest to such purpose and their role as a physician. ${ }^{17}$

"Interest" can be defined as "a commitment, goal, obligation or duty related to a particular social role or practice". ${ }^{18}$ According to this definition, interests are not inherent to relationships or roles themselves but tied to them; that is, they are context-dependent. It follows that conflicts of interest are similarly driven by circumstances and are therefore decision-specific. This is manifested in one of the most common definitions of conflict of interest, that of the US National Academy of Medicine (formerly the Institute of Medicine): 


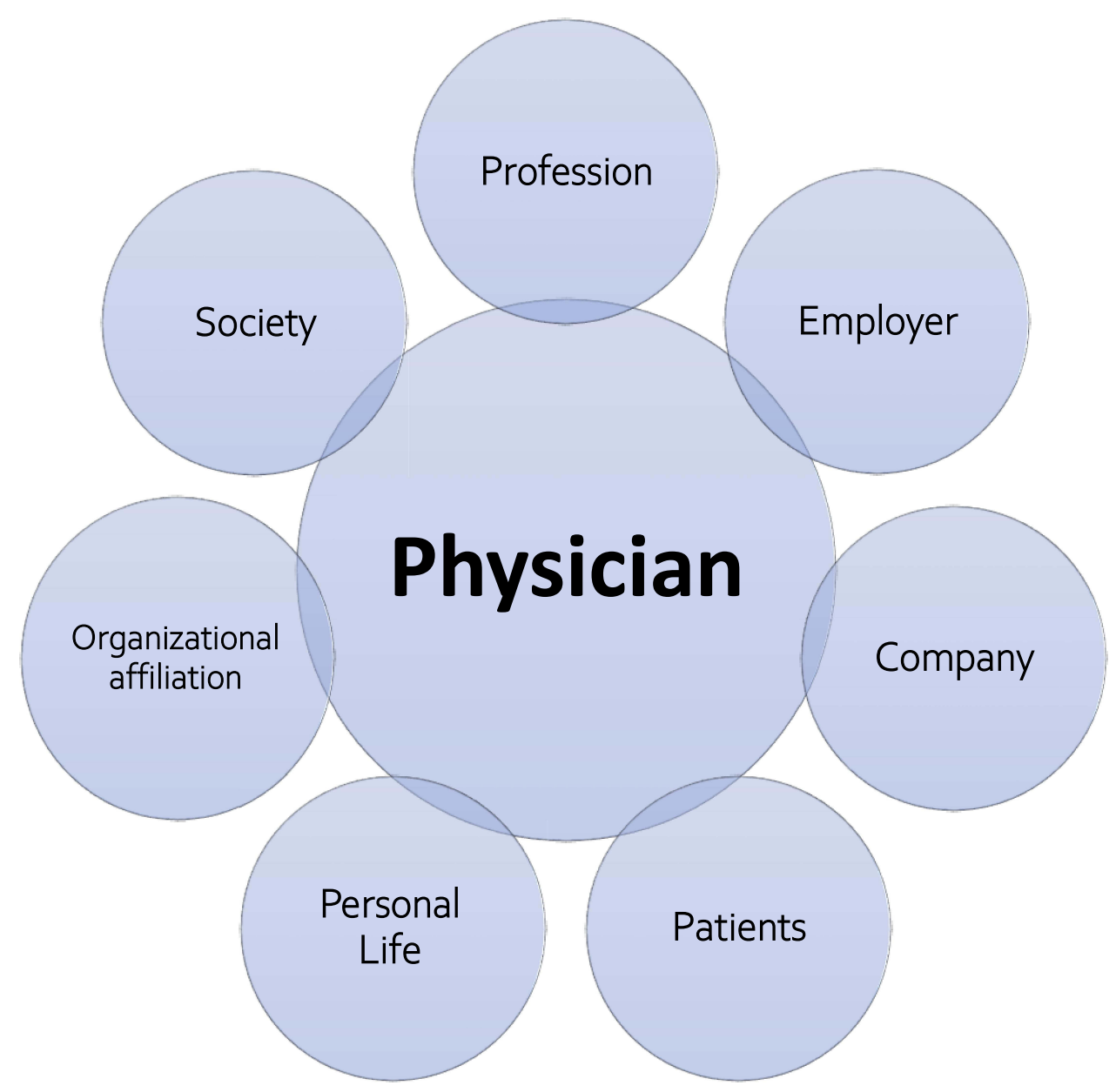

Figure I Physician-director spheres of conflict.

A conflict of interest is a set of circumstances that creates a risk that professional judgment or actions regarding a primary interest will be unduly influenced by a secondary interest. ${ }^{18,19}$

From this point of view, specific remedial actions may be required to respond to individual cases of conflict of interest in particular circumstances, as discussed below in the section of "Potential solutions".

In a medical context, common examples of primary interest are a patient's welfare or the validity of research. Financial gain is often mentioned as a form of secondary interest, although the desire for political or professional power or personal prestige could be secondary interests as well. ${ }^{20}$ Arguably, serving on a corporate board of a commercial company while practicing medicine may create the set of circumstances that would lead to a clash between these types of primary and secondary interests.

When serving on corporate boards, physicians have yet another set of rules relating to the connection between physicians and commercial companies. Physicians may encounter conflicts between their role as director and their obligations as an employee. If they serve on other boards or in official positions in organizations, they may encounter conflicts there as well. Thus, for example, the bylaws of the IMA, the legally representative organization of Israel's physicians, mandates that an official of the IMA must act with precautionary and fiduciary obligations to the IMA. Furthermore, an IMA official

may not take part in any activity nor fulfill any function that could present a conflict of interest with his or her position in the IMA, or cause him or her to act contrary to its objectives. ${ }^{21}$ 
In addition to the above, physician-directors are liable to encounter a unique set of circumstances that may pose a potential conflict of interest:

- Patient treatment - A physician developing a treatment plan may consider treating a patient with a product produced by a company where the physician serves on the Board. This situation is liable to raise inherent conflicts of interest, particularly when it comes to advising patients of the risks and benefits of the product in question, as well as alternative treatments. Similarly, when reporting side effects or other adverse outcomes from the use of the product, physician board members will face a conflict between their legal and ethical and legal duty to the patient and fiduciary duty to the company.

- Marketing - Physician participation in Board decision-making regarding marketing a company product relevant to their patients. This conflict will be magnified if the marketing is directed at the physician's place of employment. In such a case (as in others), the conflict of interest may run two ways-physicians have an obligation not to disclose commercial secrets from either side that could benefit the other.

- Clinical guidelines - A direct conflict might arise if a physician is a member of a scientific association or society involved in writing clinical guidelines for the company's product.

- Additional roles - Physicians serving on a Board will, in any event, be limited in their ability to take on other roles, depending on the capacity in which they serve. As one example, a physician serving on a company Board would be barred from serving on the Basket of Services Committee when the company with which s/he is connected has a product up for determination for inclusion in the Basket. Such a physician would not be permitted to sit on the purchasing committee of the medical institution for which s/he works, or at least not to participate in any discussions regarding the company's product or related products of other companies. Physicians sitting on a hospital board would necessarily have to refrain from serving on the compensation committee or other committees that affect their livelihood or that of their coworkers.

- Contracts or donations - Decisions of the Board regarding contracts or donations to the institution at which the physician works present an apparent conflict of interest. It should be noted that when a physician is involved in decisions that affect the business of the company's competitors, this may give rise to antitrust concerns as well. ${ }^{22}$ This particular conflict of interest is liable to be two-pronged: on one hand, the physician may be seen by the company as someone seeking to siphon funds to his or her institution or organization, and at the same time, the institution or organization may view the physician as trying to promote the company on whose board s/he serves.

- Clinical trials - Questions of which institutions a company should work with when performing clinical trials may arise when the physician works at one of the institutions in question. Even if the physician is not personally involved in the trial, and certainly if s/he is, this question cannot be objectively determined. It would be best for physicians to recuse themselves from a decision in such matters and not deal with the conflict between loyalty to the company and their employer, not to mention their personal gain.

With so many potential pitfalls, why not mark a clear demarcation and prohibit physicians from serving on boards that might give rise to a potential conflict of interest?

Paradoxically, it is the very same complicating factors that make physicians such valuable members of a Board. The presence of medical doctors on the boards of biotechnology firms has been associated with higher price-to-book ratios and firm values. ${ }^{23}$ They, more than anyone, will have their patients at the forefront of their minds and know what will appeal to them. Many have experience in quality assurance and improvement, although that should not be assumed to be an automatic correlation. ${ }^{23}$ Similarly, a physician may have professional contacts that would be invaluable to a company involved in or marketing to the medical field. On the other hand, many non-physician board members and executives feel that physicians lack the business skills to fully comprehend the issues debated at the board level. ${ }^{24}$ A lack of such understanding is likely to compromise the director's duty of care. There is a call for a "more formalized process of training for physicians being recruited for board membership", ${ }^{24}$ which is a challenge the IMA, in conjunction with the 
Hebrew University of Jerusalem, has recently taken upon itself in organizing a first-of-its-kind course for physiciandirectors.

Despite the potential conflicts, the American Medical Association (AMA) encourages physicians to join the boards of health care organizations, citing evidence that their participation on such boards is associated with "higher business performance, clinical quality, and social outcomes" and that

physicians have special expertise with complex clinical outcomes data, can add to a Board's cognitive diversity, have a reputation for altruism and can offer special competitive insights. ${ }^{25}$

This decision has been codified in the AMA Resolution H-405.953, which states, among other things, that the

AMA will advocate for and promote the membership of physicians on the boards of healthcare organizations including, but not limited to, acute care providers, insurance entities, medical device manufacturers; and health technology service organizations.

\section{Potential Solutions}

There are various mechanisms and remedies to be employed in cases of potential conflicts of interest, averting the need to throw out the baby with the bathwater:

- Full disclosure - whether to the Board or another party such as the physician's employer or body in which s/he serves as an official, is often enough of a preventative measure. Disclosure displays an openness and good faith and allows the question to be discussed and resolved. Note that disclosure may apply not only to the physician's current positions or activities, but also past ones, as well as those of close family members.

- Approval by an outside body - Sometimes the issue may need to be raised for approval by the company's audit committee or related body. Among the duties of such a committee would be to investigate potential conflicts of interest or other breaches of fiduciary duty.

- Recusal - In more problematic situations, physicians may need to recuse themselves from participating in deliberations and/or voting on a certain issue. In extreme conditions, it may not be feasible for a physician to sit on the Board of a specific company.

\section{Conclusion}

It appears that being a physician-director is a double-edged sword, with both added value for the company alongside additional risks and responsibilities. However, even after considering the complex dynamics engendered by the combination of physician and director, the assets physicians can bring to such a position would seem to outweigh the challenges presented. Recognition of the potential risks is the most basic line of defense. Therefore, physician-directors must be well versed in their various legal, ethical and professional obligations as physicians, employees and board members. But ultimately, David, and all his medical colleagues, not only can fuse these diverse roles, but should be encouraged to do so.

\section{Abbreviations}

AMA, American Medical Association; IMA, Israeli Medical Association.

\section{Ethical Approval}

Ethical approval not required.

\section{Funding}

No funding to declare.

\section{Disclosure}

The authors report no conflicts of interest in this work. 


\section{References}

1. Bestsennyy O, Gilbert G, Harris A, et al. Telehealth: a quarter-trillion-dollar post-COVID-19 reality? McKinsey \& Company: Healthcare Systems \& Services; 2021. Available from: https://www.mckinsey.com/industries/healthcare-systems-and-services/our-insights/telehealth-A-quarter-trilliondollar-post-covid-19-reality. Accessed February 4, 2022.

2. Cancherini L, Lydon J, da Silva JS, et al. What's ahead for biotech: another wave or low tide? McKinsey \& Company. Life sciences; 2021. Available from: https://www.mckinsey.com/industries/life-sciences/our-insights/whats-ahead-for-biotech-another-wave-or-low-tide. Accessed February 4, 2022.

3. Voirol C, Pelland M-F, Pelletier J, et al. How can we raise awareness of physician's needs in order to increase adherence to management and leadership training? J Healthc Leadersh. 2021;13:109-117. doi:10.2147/JHL.S288199

4. Daily CM, Schwenk C. Chief executive officers, top management teams, and boards of directors: congruent or countervailing forces? $J$ Manage. 1996;22(2):185-208. doi:10.1177/014920639602200201

5. Gabrielsson J, Minichilli A. Understanding the leadership role of the board chairperson through a team production approach. J Leadersh Stud. 2007;3(1):21-39.

6. Nicholson G, Newton C. The role of the board of directors: perceptions of managerial elites. J Manag Organ. 2010;16(2):204-218. doi:10.5172/ jmo.16.2.204

7. Boivie S, Withers MC, Graffin SD, et al. Corporate directors' implicit theories of the roles and duties of boards. Strateg Manag J. 2021;42 (9):1662-1695. doi: $10.1002 / \mathrm{smj} .3320$

8. Getz D, Buchnik T, Zatcovetsky I. Indices for science, technology and innovation: data infrastructure. Final report. Hebrew. Samuel Neaman Institute; 2019.

9. Daniely Y. Israel's challenging transformation from start-up nation to scale-up nation. In: Dutta S, Lanvin B, Wunsch-Vincent S, editors. Global Innovation Index 2020: Who Will Finance Innovation? Thaca, Fontainebleau, and Geneva: Cornell University, INSEAD, and WIPO. 2020:165-170

10. Xu Q, Boggio A, Ballabeni A. Countries' biomedical publications and attraction scores. A PubMed-based assessment. F1000Res. 2015;3:292. doi:10.12688/f1000research.5775.2

11. Ministry of Health. Digital health program. Hebrew; 2017.

12. Sec. 254 (a) (1-3) Companies Law, 5759-1999, LSI 4477.

13. Torts Ordinance (New Version). Hebrew; 1968.

14. Buchbinder v. The Official Receiver, Civil Appeal 610/94, 332 (2003).

15. Coates J. Responsibilities of doctors in management and governance. NZ Med J. 2001;114:95.

16. Cruess SR, Cruess RL. Professionalism and medicine's social contract with society. Virtual Mentor. 2004;6(4):185-188.

17. Sec. 10 Physicians' Ordinance (New Version), 5737-1976, LSI 382.

18. Komesaroff PA, Kerridge I, Lipworth W. Conflicts of interest: new thinking, new processes. Intern Med J. 2019;49(5):574-577. doi:10.1111/ imj. 14233

19. Lo B, Field MJ, editors; Institute of Medicine (US) Committee on Conflict of Interest in Medical Research, Education, and Practice. Conflict of interest in medical research, education, and practice. Washington (DC): National Academies Press (US); 2009.

20. Thompson DF. Understanding financial conflicts of interest. $N$ Engl J Med. 1993;329(8):573-576. doi:10.1056/NEJM199308193290812

21. IMA Regulations. Section 39.1 (Hebrew); 2018. Available from: https://www.ima.org.i1/main/ViewContent.aspx?CategoryId=3485. Accessed January $5,2022$.

22. Sagin T. The pros and cons of physician participation. Healthc Exec. 2019;4:62-64.

23. Houston C, Graham JE, Schuhmann P. Biotechnology valuation and governance: drug development and board of directors composition. $J$ Commer Biotechnol. 2013;19(1):7-23. doi:10.5912/jcb561

24. Satiani B, Prakash S. It is time for more physician and nursing representation on hospital boards in the US. J Hosp Medl Manage. 2016;2:44-46.

25. Miller RN. Physicians encouraged to take seat at table on health care boards. Available from: https://www.ama-assn.org/practice-management /scope-practice/physicians-encouraged-take-seat-table-health-care-boards. Accessed June 6, 2021.

Journal of Healthcare Leadership

Dovepress

\section{Publish your work in this journal}

The Journal of Healthcare Leadership is an international, peer-reviewed, open access journal focusing on leadership for the health profession. The journal is committed to the rapid publication of research focusing on but not limited to: Healthcare policy and law; Theoretical and practical aspects healthcare delivery; Interactions between healthcare and society and evidence-based practices; Interdisciplinary decision-making; Philosophical and ethical issues; Hazard management; Research and opinion for health leadership; Leadership assessment. The manuscript management system is completely online and includes a very quick and fair peer-review system. Visit http://www.dovepress.com/testimonials.php to read real quotes from published authors.

Submit your manuscript here: https://www.dovepress.com/journal-of-healthcare-leadership-journal 